\title{
Intertrial movements during distributed shock-escape conditioning'
}

\author{
H. W. COPPOCK AND J. G. OSBORNE \\ ARIZONA STATE UNIVERSITY
}

\begin{abstract}
A factorial experiment employed 40 rats in a 2-choice shock-escape situation. Reversal theta was nonsignificantly lower following amphetamine than saline, and significantly lower with a $180 \mathrm{sec}$. than with a $20 \mathrm{sec}$. intertrial interval. Since intertrial movements were more frequent with amphetamine and with the $180 \mathrm{sec}$. interval, it is suggested that the number of intertrial movements be controlled in studies of distribution and successive reversals.
\end{abstract}

\section{Problem}

The rate of change in performance from trial-to-trial in a conditioning situation depends in part on retention of effects of the last reinforcement. Retention may be more dependent on intertrial behavior than on intertrial time (Jenkins \& Dallenbach, 1924; Minami \& Dallenbach, 1946)。A decrement in performance is to be expected on a succeeding trial to the extent that movement between trials disrupts a motor set, as in delayed reaction tests (Hunter, 1913; Fletcher, 1964), and to the extent that movement provides fluctuation of the elements of the stimulus situation. Differences in unobserved intertrial movement may account for some of the discrepancies among reports of the effects of intertrial time and successive reversals.

In order to determine the role of intertrial movement we compared the effects on rate of conditioning of two independent variables, each of which influences intertrial movement: intertrial time and amphetamine.

\section{Method}

Records of 40 naive Holtzman male rats, 200-360 gm, were obtained in a factorial experiment employing two intraperitoneally injected drugs, amphetamine sulfate at the dosage of $.5 \mathrm{mg} / \mathrm{kg}$ in saline solution vs an equivalent volume $(2.5 \mathrm{cc} / \mathrm{kg})$ of saline; and two intertrial (intershock) times, $20 \mathrm{sec}$. vs $180 \mathrm{sec}$. To allow time for drug action in the $20 \mathrm{sec}$.group, injection occurred $1 \mathrm{hr}$. prior to trial 1; in the $180 \mathrm{sec}$. group, $3 \mathrm{~min}$. prior to trial 1. At least a beginning drug effect on reaction threshold would be present in both groups during all trials; and at or near the 21st trial, time since injection would be equal for both drug groups.

Nineteen prereversal trials were followed by 20 reversal trials of 2-choice shock-escape conditioning of head movement into positions greater than 50 degrees lateral to the usual center position. The rat was confined in a closely fitting cage (Coppock et al, 1963), and photoelectric cells recorded not only trial movements but also intertrial movements. The "correct" movement which terminated shock during prereversal was toward the side opposite to the position first entered on trial 1. Trial performance was categorized as failure if an incorrect movement occurred during shock, and as success if the correct choice occurred without any incorrect movement. All Ss necessarily "failed" on trial 1.

\section{Results: Prereversal}

Total failures were not significantly affected by treatments. Asympotic probability of success was estimated by the proportion of successes on the last 10 of the trials. The grand mean was .85 and was not significantly influenced by either of the independent variables.

The parameter $\theta$, the fractional increment in probability of success from trial-to-trial, was estimated by a least squares fit of a linear model (Estes \& Lauer, 1957) to the sequence of successes and failures of each rat. Analysis of variance indicated no significant treatment effects.

Intertrial movements were tallied, irrespective of side, and the mean was greater in the amphetamine groups $(p<.05)$ and, of course, greater in the $180 \mathrm{sec}$. groups $(p<.02)$.

\section{Results: Reversal}

Theta was evaluated for each record by taking the difference between unity and the prereversal asymptote as the estimate of inital probability of success for the reversal series. Analysis of variance indicated only one significant $\mathrm{F}$ ratio: Mean $\theta$ at $180 \mathrm{sec}$. was lower than at 20 sec. $(p<.02)$ (Table 1). There were no significant treatment or interaction effects on asympototic probability, nor on mean reciprocal latency. However, as Table 2 indicates, intertrial movements were greater in the amphetamine groups $(p<.10)$ and in the 180 sec. groups $(p<.01)$ 。

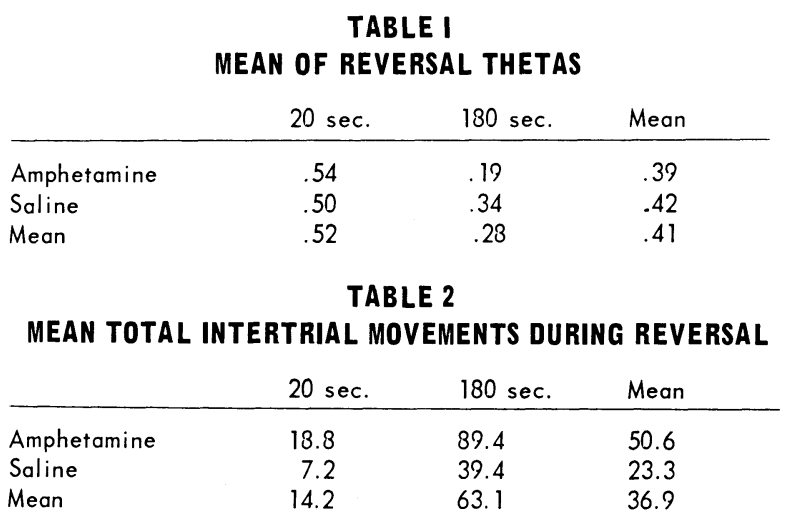




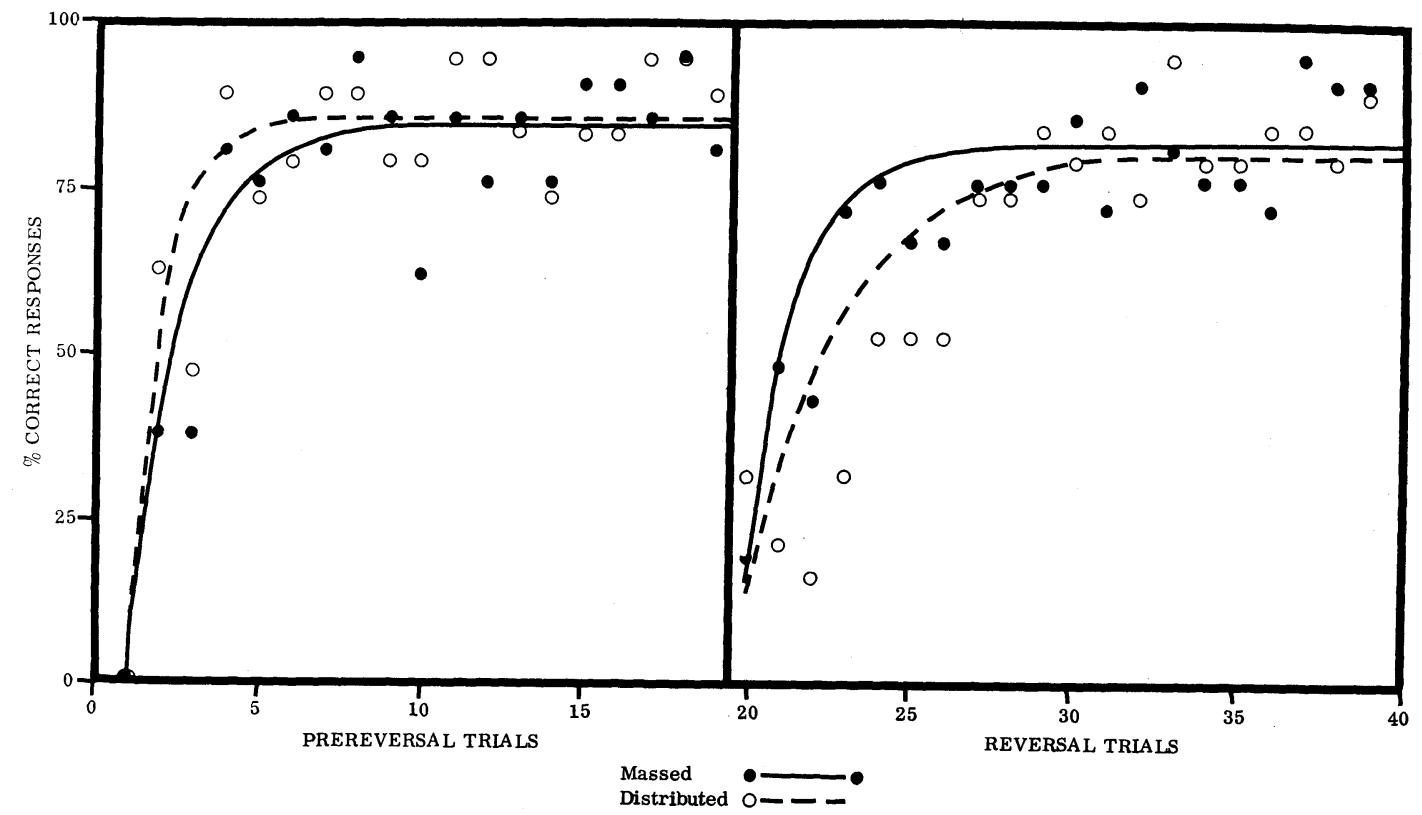

Fig. 1. Probability of success for groups with 20 sec. intertrial interval (Massed Practice) and 180 sec. intertrial interval (Distributed Practice).

\section{Diseussion}

During reversal, when time since injection was comparable for all groups, conditioning was slower in the groups which were making more intertrial movements, whether movements were encouraged by drug or by time. This facilitating effect of massing on early reversal performance is consistent with a few other data (Fletcher \& Cross, 1964; Fletcher, 1964) and with the over lapping of elements on successive trials (Estes \& Lauer, 1937; Prokasy, 1961). It is possible, also, that the increased number of intertial movements indicating or producing greater stimulus fluctuation, may be responsible for the effect of both of the independeat variables on $\theta$. The probability of this inference is greater when one considers in addition the effects of amphetamine and other drugs (Coppock et al, 1963) and the increased trial-to-trial retention following phenobarbital, which decreased inter-trial movements into the "incorrect" position (Coppock, 1962).

The lower reversal $\theta$ of the $180 \mathrm{sec}$. groups is also consistent with the generalization that rate of reversal conditioning is inversely related to the number of prereversal reinforcements for the response pattern of error-plus-correction, i. e., the number of prereversal trials eliciting "alternation" or struggling (Coppock et $a l, 1963$ ).

The positive acceleration of reversal learning at 180 sec. is typical of other data from this situation (Coppock et al., 1963) and is more consistent with an all-or-none than with an incremental model (Bower \& Theios, 1964; Coppock \& Freund, 1962).

Although constancy of $\theta$ during successive reinforcements (and successive reversals) is assumed by the simplest version of the stimulus fluctuation model, constancy of intertrial position and activity is rarely reported in the literature. It is suggested that intertrial behavior be minimized and measured not only during the explicit conditioning of position preference, but also during the implicit unconditioning of position preference, which is said to be a major process in the conditioning of visual ("object") preference (Harlow, 1959).

\section{References}

Bower, G. H., \& Theios, J. A learning model for discrete performance levels. In R. C. Atkinson (Ed.), Studies in mathematical psychology. Stanford, California: Stanford University Press, 1964. Pp. 1-31.

Coppock, H. W. Phenobarbital improves retention and impairs reversal learning of shock escape in the rat. Psychol. Rec., 1962 $12,367-372$.

Coppock, H. W. , \& Freund, J. All or none vs incremental learning of errorless shock escapes by the rat. Science, 1962, 135, 318-319.

Coppock, H. W., Meeks, W. A., \& Huard, D. V. Drug and strain effects on performance and reversal of a head-position habit. J. comp. physiol. Psychol., 1963, 56, 551-557.

Estes, W. K., \& Lauer, D. W. Conditions of invariance and modifiability in simple reversal learning. J. comp. physiol. Psychol., 1957, 50, 199-206.

Fletcher, H. J. Activity during delay interval and delayed response errors in monkeys. Psychcl. Rep., 1964, 14, 685-686.

Fletcher, H. J., \& Cross, H. A. Effects of trial 1 reward contingency, intertrial interval, and experience on intra problem discrimination performance of monkeys. J. comp. physiol. Psychol., 1964, 57, 318-320.

Harlow, H. Learning set and error factor theory. In S. Koch (Ed.), Psychology: A study of a science. Vol. 2. New York: McGrawHill, 1959. Pp. 492-537.

Hunter, W. S. The delayed reaction in animals and children. Behav. Monogr., 1913, No. 6.

Jenkins, J. G., \& Dallenbach, K. M. Oblivescence during sleep and waking. Amer. J. Psychol., 1924, 35, 605-612.

Minami, H., \& Dallenbach, K. M. The effect of activity upon learning and retention in the cockroach. Amer. J. Psychol., 1946. 59, 1-58.

Prokasy, w. F. Nonrandom stimulus sampling in statistical learning theory. Psychol. Rev., 1961, 68, 219-224.

\section{Note}

1. Supported in part by NIMH Grant MY-2926. Based on a paper read at the Midwestern Psychological Association Meeting at St. Louis, 1964, which reported data obtained in master's thesis research by the junior author. 